\title{
The Implementation of Formal Assessments in Intermediate Phase Mathematics as a Foundation of Teaching and Learning Enhancement
}

\author{
Senzeni Sibanda ${ }^{1}$, Awelani M. Rambuda ${ }^{2, *}$ \\ ${ }^{1}$ Faculty of Humanities, Department of Postgraduate Studies in Education, Central University of Technology, Free State, South Africa \\ ${ }^{2}$ Faculty of Humanities, Department of Educational and Professional Studies, Central University of Technology, Free State, South \\ Africa
}

Received June 27, 2021; Revised August 4, 2021; Accepted September 21, 2021

\section{Cite This Paper in the following Citation Styles}

(a): [1] Senzeni Sibanda, Awelani M. Rambuda, "The Implementation of Formal Assessments in Intermediate Phase Mathematics as a Foundation of Teaching and Learning Enhancement," Universal Journal of Educational Research, Vol. 9, No. 12, pp. 1915 - 1927, 2021. DOI: 10.13189/ujer.2021.091204.

(b): Senzeni Sibanda, Awelani M. Rambuda (2021). The Implementation of Formal Assessments in Intermediate Phase Mathematics as a Foundation of Teaching and Learning Enhancement. Universal Journal of Educational Research 9(12), 1915 - 1927. DOI: 10.13189/ujer.2021.091204.

Copyright $\bigcirc 2021$ by authors, all rights reserved. Authors agree that this article remains permanently open access under the terms of the Creative Commons Attribution License 4.0 International License

\begin{abstract}
The purpose of this research was to explore how intermediate phase mathematics teachers implemented formal assessments to enhance teaching and learning. The research was elicited by several reports on the underperformance of South African learners in mathematics. The constructivist philosophy was embraced to underpin the study, specifically, Piaget's theory of cognitive constructivism. The research adopted an interpretivist paradigm and a phenomenological research design. The study employed purposive sampling to select nine grade 4 to 6 mathematics teachers who were interviewed, and data were gathered through semi-structured interviews. Data analysis was done through the themes that emerged from participants' responses. Results of the research revealed that some teachers did not align assessment in mathematics to theories of education. In this case, the constructivist theory was informed in the study. Some teachers faced challenges in formal assessment implementation because they were not trained to teach in the intermediate phase. Instead, they were trained to teach in other phases. Additionally, the South African Department of Basic Education did not adequately train teachers in formal assessments. Learners had difficulties in understanding word sums, hence making it difficult for them to solve complex procedures in mathematics. The study, therefore, recommends that
\end{abstract}

teachers be involved in curriculum design. Teachers must be placed according to the subjects and phases they are qualified for. Teacher training institutions should practically help in the training of mathematics teachers to implement formal assessments effectively. Teachers should be continuously developed by their mathematics subject advisors and lastly, teachers need to continue developing themselves to keep abreast of current developments in the teaching and learning of mathematics.

Keywords Assessment, Cognitive Constructivism, Constructivist Theory, Curriculum and Assessment Policy Statement, Formal Assessment, Intermediate Phase, Mathematics, Mathematics Learning, Mathematics Teaching, Social Constructivism

\section{Introduction}

Statements such as "assessment drives learning" and "students respect what is inspected" are typically centred in the studies complementing the influence that assessments have on accumulating learning by encouraging learners to become involved in their learning process [1]. Learner assessment assists teachers to obtain 
information that is significant for decision-making in the classroom, consequently, improving the performance of learners [2]. In harmony with the idea, South Africa has also adopted assessment as an essential factor for enhancing teaching and learning in schools [3]. Formal assessments have a profound influence on getting feedback from learners' achievements and monitoring whether objectives are attainable. These assessments comprise the School-Based Assessment (SBA) and the final test for a particular grade [4]. The assessment program has an alternative of following diverse modes; though the Department of Basic Education (DBE) proposes the suitable format of tasks to be used in the subject [4]. The DBE recommends that formal assessment tasks in intermediate phase mathematics should be in the form of tests, examinations, assignments, investigations, and projects. Reference [5] mentions that in formal assessments, constructive formative feedback is offered to develop learners' knowledge and skills. The authors in [6] assert that formal assessments help learners to move forward in their learning, to 'form' or shape their development. Formal assessments are opposed to summative assessments, which focus only on the product or outcome of learning.

This study is elicited by various reports on the underachievement of South African learners in mathematics. Regardless of many years of mathematical development programs, there is still inadequate progress in the development of learners in South Africa. This is revealed by poor results and performance as reported by the Trends in International Mathematics and Science Study (TIMSS), Southern African Consortium for Monitoring Education Quality (SACMEQ) and the Annual National Assessments [7, 8]. Furthermore, reference [9] confirms that South Africa is enormously underperforming in education, particularly in mathematics teaching and learning. As an example, the pass rate for mathematics was lowered to $20 \%$ from $40 \%$ to keep the learners moving through to the next grade or phase [10]. In response to the above, the author in [11] has encouraged teachers to work harder in developing effective assessment systems that improve learning in South Africa. This statement implies that there is high underperformance in mathematics. The frequent failure of learners in mathematics has been the concern of all stakeholders in education. Reference [12] argues that teachers perceive formal assessments as the most tedious part of their job which involves the most administration. Additionally, some learners confirm that they dread assessment time. On the contrary, learner involvement in assessment activities can be valuable in their knowledge enrichment. This can be achieved if teachers can concentrate on actively engaging learners in presenting their prior knowledge of the subject. This, in turn, encourages learners to complete the tasks. If assessment tasks are meaningful and exciting, learners might put in more effort if they are given the freedom to be creative and use their own strengths, the results may well be outstanding. This is very effective in the learners' achievement and at the same time makes teachers' tasks as evaluators easier [12]. The authors of [13] and [14] assert that issues like teacher's beliefs in formal assessments, lack of knowledge of formal assessments, training and experience affect teachers' effective implementation of these assessments.

Whilst formal assessment is incorporated in government policy documents, there is inadequate evidence based on research to confirm whether teachers implement assessments properly and adequately. Furthermore, research still indicates that although several studies have been carried out on teacher assessment practices, there has been limited research on teachers' assessment literacy in South Africa [14]. Additionally, a greater number of teachers have inadequate proficiency in the implementation of formal assessments and lack proper guidance and support in this aspect. There is an inadequacy of assessment knowledge and practice amongst teachers. Furthermore, large gaps in the knowledge of assessment practices have been noted [15]. Resultantly, further study on how frequently teachers need to carry out assessments for teaching and learning enhancement and consider the reliability and validity of SBA is essential [16].

The aim of this study was to explore the implementation of formal assessments in intermediate phase mathematics as a foundation of teaching and learning enhancement. Therefore, this study investigated the following research questions:

- What forms of assessment are implemented in mathematics teaching and learning?

- What are the challenges experienced by teachers in the implementation of formal assessments?

- What are the challenges experienced by learners when they are engaged in formal assessments?

- How do mathematics teachers support and guide learners after they have received formal tasks to give them quality feedback?

\section{The Teaching, Learning and Assessment of Learners in Mathematics}

Reference [4] specifies the aims and skills which learners must develop in the learning of mathematics. Mathematics teaching must follow a constructivist approach whereby learners are taught problem-solving approaches. In this way, learners become actively involved in the exploration, prediction and conjecturing of facts. These promote learners' abilities to discover solutions for authentic obstacles in everyday life situations [17]. Additionally, the work in [18] suggests a mathematical proficiency guideline which is an inclusive view of mathematics teaching and learning. It consists of 
five strands to be followed which include:

- in-depth understanding of basic operations;

- ability to calculate accurately and efficiently;

- proficiency in formulating, representing and solving mathematical problems;

- critical thinking to reflect and justify mathematical problems and come up with solutions; and

- view mathematics as a useful and valuable subject in everyday life situations.

These strands are compatible with the aims and specific skills as stipulated in the Curriculum and Assessment Policy Statement (CAPS) [4].

\subsection{Assessment of Learners in Mathematics}

Assessment in South African schools is guided by the CAPS which stipulates the nature of formal assessments and the minimum requirements for intermediate phase mathematics. Assessment in mathematics is guided by goals and principles [4]. The author in [19] asserts that formal tasks for assessment purposes must be developed in a manner that they ensure the trustworthiness of results. This can be achieved if assessments are evaluated through three general properties, namely reliability, validity, and fairness. Similarly, reference [20] mentions that reliability; validity and fairness are the significant principles which punctuate good assessment practices. Additionally, the assessment must give feedback to the learners on the quality of their work and provide an overview of how to enhance performance [21].

\subsection{Challenges in Mathematics Teaching, Learning and Assessment}

Evidently, formal assessments play a notable role in the teaching and learning of mathematics; however, there are challenges in the implementation of formal assessments, for both the teachers and learners. Some of the teachers have insufficient instructional knowledge of mathematics as a subject, resultantly; they become bound to the textbooks, resorting back to teacher-centred methods which do not promote constructivist theories [18, 22]. Some learners develop mathematical anxiety; thus, they fear the subject and avoid it wherever possible [23]. Similarly, reference [24] argues that mathematical anxiety can be attributed to teachers' inadequacy to interpret concepts very well. The work in [25] further claims that some teachers view formal assessments as an administrative burden owing to their lack of knowledge of formal assessments [26]. However, these challenges can be alleviated to enhance teaching and learning of mathematics.

\subsection{Accommodating Challenges in Mathematics Teaching, Learning and Assessment}

Accommodation in assessment is a process of modifying the previous strategies which were employed in assessment. New strategies were come up with which will address challenges encountered by the learners [27, 28]. Inadequacy of instructional expertise on the part of teachers may be addressed through teacher's development and Professional Learning Communities (PLC). Through PLCs, teachers gain new ideas on how to enhance teaching and learning of mathematics, stretching to the implementation of formal assessments [29, 30]. Reference [31] argues that learners' anxiety about mathematics can be reduced through the implementation of teaching strategies which include critical thinking, cooperative learning, assisting learners to connect mathematics to real-life situations, embrace learners varied learning styles and motivate learners to develop strong skills and positive attitudes towards mathematics. These will enable learners to discover and construct mathematical knowledge, a process that would enhance their understanding of the subject.

\subsection{Piaget's Cognitive Constructivism Theory}

Piaget's cognitive constructivism has its focal point on the intellectual activities that individuals employ to understand the universe [32]. Furthermore, it is the methodology of learning whereby learners are exposed to constructing links among notions and facts being taught. This puts emphasis on actively engaging learners to construct knowledge for themselves [33]. In this theory, reference is made that children are continually exposed to new information which they try to organise and understand. Explanation is given that understanding takes place through connected processes namely, assimilation, accommodation, and equilibration.

\subsubsection{Assimilation}

The authors in [34] define assimilation as the utilisation of prevalent ideas in the clarification of first concurrencies. It is the process of using already operating schema to give meaning to emerging experiences [18]. Reference [32] claims that at the time when latest findings arise that are well suited for the child's present knowledge map, assimilation develops, and this is also when present ideas are employed to interpret the latest occurrences surrounding the child. The work in [34] presents a practical example of assimilation in the teaching and learning of mathematics in the intermediate phase. This is illustrated below:

How experiences promote development

If learners are given a problem like the one illustrated below to solve:

$$
67
$$

\section{$-33$}

and they get 34 as an answer. Their subtracting-whole-numbers scheme suggests that they 
subtract smaller numbers from larger ones. However, if they are given this problem:

and they also get 34 as an answer, they have mistakenly-assimilated the new experience into their existing scheme. Their thinking did not change, and they still subtracted the smaller numbers from the larger ones, ignoring the positioning of the numbers [34]. This calls for the teacher to model and explain the process of regrouping numbers in subtraction so that in turn, the learners can solve a variety of problems.

The authors in [35] illustrate assimilation in teaching the number line, in numbers' operations and relationships. They explain that for example, a learner who has already mastered the 2 and 10 number lines will be able to count in $8 \mathrm{~s}$, as counting in $8 \mathrm{~s}$ means adding 10 and subtracting 2 or subtracting 10 and adding 2 on a number line. New information of counting in $8 \mathrm{~s}$ will easily correspond with the child's present map of counting in $2 \mathrm{~s}$ and $10 \mathrm{~s}$.

\subsubsection{Accommodation}

Accommodation is the process of changing one's reasoning to construct fresh ideas or modify outdated ones when they are irrelevant to the current realities. This happens when current information surfaces that dispute with the child's current schemes leading to a need to modify the new format of understanding to accommodate current situations [34]. Similarly, accommodation is the procedure of modifying unfit ideas to suit the existing conception [18]. An example of accommodation is demonstrated in teaching space and shape, properties of 2-dimensional shapes where both a square and a parallelogram are quadrilaterals. Learners have prior knowledge of a square, having four sides of equal lengths and four right angles. A new quadrilateral, parallelogram, is introduced which in this case contradicts the child's existing map. This requires modification of a child's map to accommodate the characteristics of a parallelogram as a new quadrilateral introduced [36].

\subsubsection{Equilibration}

Reference [37] describes equilibration as a state of cognitive order, balance, and predictability that one describes in the overview. It is a condition which is arrived when one's experiences make sense and make one's world predictable. Furthermore, this happens when assimilation and accommodation persistently collaborate. Continuous accommodations create opportunities for assimilations to occur and conversely, in ever-increasing patterns. These ever-increasing patterns must be kept in equilibrium throughout the child's emerging maps regarding complete perception of the environment [37]. The authors in [34] assert that development advances when knowledge and skills increase due to equilibrium being disrupted and restored. Equilibration is likely to happen in the teaching of, for example, equivalent fractions. Reference [36] demonstrates this concept using the fraction wall and the number line as indicated below:

- Which one is greater; two quarters $(2 / 4)$ or a half $(1 / 2)$ of a pizza?

- A Fifth $(1 / 5)$ or two tenths $(2 / 10)$ of R200? This opens the idea that fractions can be converted to make them equivalent.

\section{Methodology}

This is an interpretative qualitative study which is grounded in phenomenological design. Qualitative research is an investigation procedure which requires the researcher to develop a comprehensive depiction of the phenomenon. The researcher must analyse the views of participants and write a detailed report afterwards. It must be conducted under natural settings, studying things as they are [38]. The main point of qualitative research is to inquire and gain acquaintance of a fundamental phenomenon currently being explored in a particular qualitative study [39]. Qualitative research is characterised by using general and broad questions which endeavour to elicit rich information on the participant's views. Individuals with sound knowledge and experience of the phenomenon under study are purposefully sampled to participate [40]. Phenomenology is the study of an individual's awareness derived from one's opinion. It describes ideas related to how they are perceived by participants in given circumstances. It goes together with qualitative data gathering methods such as interviews and observations. Additionally, it seeks inquiry regarding the meaning of experience from participants [41]. The researchers conducted semi-structured interviews with intermediate phase mathematics teachers. The participants chosen were ideal for the study since they had experiences of the phenomenon being studied, they had an average of twelve years experience in mathematics teaching. Purposive sampling, which is classified under a non-probability sampling method, was utilised to select the research participants. The authors in [42] mention that this method of sampling is applied with a clearly defined aim in mind, in this instance, with the purpose of obtaining information on how formal assessments were implemented in intermediate phase mathematics teaching and learning. Nine teachers were sampled, three from each grade, thus from Grades 4 to 6 . Of the nine participants sampled, four were males and five were females with an average age of 35 years old. The researchers ensured that the ethical guidelines were observed by doing the following:

- The researchers made a presentation of their research proposal to the Title Registration Committee (TRC) of the Faculty of Humanities for its approval. The 
research proposal was submitted to the Faculty Research and Innovation Committee (FRIC) of the Faculty of Humanities for approval.

- Ethical clearance certificate was granted a number by FRIC [D. FRIC.08/18/7]. The researchers completed a research application form to seek permission from the Free State Department of Education to conduct the research at schools. The department granted approval with attached conditions.

- The researchers carefully considered all possible consequences for teachers who participated in this research.

- The researchers ensured that the consent of sampled teachers was discretionary and informed, devoid of any inferred punishment for rejecting to take part and with respect to their anonymity. The researchers told the participants that they could withdraw from taking part at any point of the research.

During the interviews, data were recorded using a cellular phone by the researchers and interviews were done after normal teaching time. Data were then transcribed following the steps discussed below.

- The researchers re-examined the statements that are related to the topic, then semantic units such as paragraphs and phrases relevant to the questions were noted.

- The researchers verified if the phrases were relevant to the phenomenon (the implementation of formal assessments in intermediate phase mathematics teaching and learning).

- Data were consolidated, which was the process of changing provisional themes which emerged and formulating sub-themes under each main theme identified from the individualised semi-structured interviews with teachers on how formal assessments were implemented.

- The researchers further evaluated the data for adequate confirmation and applicability to the study.

- Themes and sub-themes were finally tabulated, and this made it more clear-cut for the researchers to do data analysis and draw conclusions thereafter.

\section{Results}

\subsection{Theme 1: The Forms of Assessment Implemented in Mathematics Teaching and Learning}

Analysis of interview data has revealed that intermediate phase mathematics teachers are knowledgeable with forms of formal assessments used.

4.1.1. Sub-theme 1: Teachers' Knowledge of the various Forms of Formal Assessments Implemented in Intermediate Phase Mathematics Teaching and Learning
Almost all the teachers interviewed seemed to be knowledgeable about the forms of assessment used in intermediate phase mathematics teaching and learning as stipulated in the CAPS policy document. However, T3's response indicated that he lacked the knowledge of the SBA requirements. This was depicted in his response when asked about the various forms. T3 stated:

The forms of assessment? Mm... I use the textbook and the teacher's guide, or if I see that the form of assessment is going to be very challenging for learners, I go out and search for an adequate form of assessment. (T3).

T3's view clearly indicates that he does not have the knowledge of the SBA requirements according to the CAPS policy.

\subsection{Theme 2: Challenges Experienced by the Teachers in the Implementation of Formal Assessments}

Teachers are challenged as they implement formal assessments. Teachers identified challenges in teaching and learning resources, workload, class size, and parental involvement.

\subsubsection{Sub-theme 1: Lack of Teaching and Learning Resources}

Teachers had great concern over the inadequacy of teaching and learning resources. They indicated that this affects their proper implementation of assessments too. $\mathrm{T} 1$ had this to say:

We don't have enough books here; we sometimes receive the Rainbow books very late maybe towards the end of term 1. We don't even have materials to construct objects in projects and investigations. It is really a challenge; it affects proper planning. (T1).

T8 shared the same sentiment when he added that: Allocation of resources are a challenge, we have problems with copiers, calculators. We really have problems with stationery; it disturbs our planning a lot. (T8).

\subsubsection{Sub-theme 2: Assessment Brings too much} Workload on the Teachers

Most of the teachers pointed out that the implementation of formal assessments burdens them with a heavy workload. There is no time allocated on the timetables that are specific for assessment. For instance, T3 said:

Emphasis is on neatly designed assignments which takes most of our teaching time. I am not computer literate and the school knew about this when they hired me. Our tasks are returned back during the moderation process by our HODs just because they do not have for example, headers or footers, this derails my work. (T3). 
T6 echoes the opinion that assessment has too much paperwork when pointing out that:

Our HODs do not take into consideration some of the periods are taken for assessments, those done in class. They don't understand when we are behind with curriculum coverage that we sometimes assess during the normal teaching time. It is a lot of work to assess learners individually for a project too or an investigation. (T6).

\subsubsection{Sub-theme 3: Large Class Sizes}

Class size was identified as one of the challenges which have impacted negatively on the teachers in the implementation of assessments. Most of the teachers stated that their classes were too big and overcrowded, which is against the ideal teacher-learner ratio of 1:35 as stated by the DBE. According to T4:

I can't assist my learners individually, sometimes the period is over before group feedback is done because there are also too many groups in one class. Learners are overcrowded, we were promised by the department in 2012 when we had CAPS training that this will be solved, instead, they keep on enrolling learners without building more classrooms and employing other teachers. (T4).

In agreement with $\mathrm{T} 4, \mathrm{~T} 2$ confirmed overcrowding issue when stating that:

I have 51 learners in my class, meaning I have to mark 51 projects or investigations. I end up grouping them even though the rubric states they must be individually assessed. (T2).

On the contrary, $\mathrm{T} 6$ 's class is found to be suitable for assessments; hence there is no problem of overcrowding at all. Ten minutes are allocated every day to check how far the learners are with the project and $\mathrm{T} 6$ assists them wherever necessary. T6 had this to say:

Projects or assignments are not submitted the day they are given out. I give my learners time to go and collect data like now they are busy with data handling in grade 6. We work stage by stage until the project is finished according to the due date stated. I have 23 learners in my class, the number is quite easy to handle. (T6).

The researchers have however noted that class sizes are a challenge to quintile 1,2 and 3 schools where the learner-teacher ratio is not practical. Quintile 4 and 5 schools' classes were not overcrowded; hence teachers were not challenged in this aspect.

\subsubsection{Sub-theme 4: Lack of Parental Involvement}

Teachers raised a concern that most parents lacked involvement in their children's homework. Some of the learners did not get any form of assistance from home pertaining to their schoolwork. Assignments to be done at home were either lost or returned incomplete. For example, T1 said:

Lack of support from home, Eh, I even know of learners who can tell you I am very tired I have been watching a movie last night with a parent, yet home works are not done. Parents must know that schoolwork comes first and support us, especially when we send projects home. (T1).

Interestingly, $\mathrm{T} 6$ also confirmed that some parents were not committed to their children's homework when he said: Some parents don't even sign the marked tests we send home, just to acknowledge they received the work of their children. Worse... when it comes to assisting them in assignments, it is a nightmare, I just let my learners collect information or materials to be used then they work in class under my supervision. (T6).

\subsection{Theme 3: Challenges Experienced by the Learners When they Are Engaged in Formal Assessments}

During interviews held with intermediate phase mathematics teachers, there was a revelation that learners were challenged as they engaged in formal assessments. The learners had language problems, they were afraid of mathematics, and some contextual factors were not conducive to effective teaching and learning.

\subsubsection{Sub-theme 1: Language Barrier}

The interviews held with the teachers revealed that the Language of Learning and Teaching (LoLT), thus English language made it difficult for learners to understand assessment instructions. This poses a challenge for learners to achieve in mathematics as they do not understand word problems either. This was confirmed by T7 who said:

The major challenge is on language understanding and also what I have noticed is that most of us who are teaching mathematics, tend now to divert the use of English trying to let learners understand, but not knowing that we are spoiling learners because the assessment will be purely in English, now when assessed it becomes difficult. (T7).

In accordance with T7's statement, T5 concurred by saying that:

Learners misinterpret questions; you will find that learners have a poor understanding of the English language. One can explain during an assignment or project but a subject teacher cannot assist learners in tests and examinations and they struggle a lot during examinations. (T5).

4.3.2. Sub-theme 2: Learners' Beliefs and Attitudes towards Mathematics as a Subject

Negative attitudes towards mathematics and the fear of mathematics were identified as a challenge to the learners during the interviews held with mathematics teachers. 
This is evident in T4's statement:

This happens several times, they fear mathematics, they have psychological fear, activities they do very well under informal conditions are badly done when given as formal tasks. (T4). that:

This concern was also confirmed by $\mathrm{T} 2$, who alluded

Learners generally believe that mathematics is difficult. We have to demystify that, show learners that it is possible. We have to tell them it can be done, we have to make noise about how easy maths can be, make it very interesting through games etc. (T2).

\subsubsection{Sub-theme 3: Contextual Factors}

Teachers highlighted that contextual factors were a challenge to teaching and learning, hence having a negative impact on assessment. Issues like learners being exposed to communities with bad habits, poverty, poor parental education, and inadequate access to health care services were pulled into focus as having a major effect on teaching and learning. This is demonstrated by T6's response:

Socioeconomic factors, child-headed families, no one to monitor them at home; all these contribute to hardships in learners. There is totally no follow up at home. Assignments projects are done at home end up being done here, at school, by us again and it means there is no true reflection of what the learner achieves. (T6).

This was also supported by T4, who remarked that: Some learners are absent during assessment time, this might be due to ill-health, which is mostly from lack of care from parents, or lack of getting immediate attention when sicknesses are at a lower stage. (T4).

\subsection{Theme 4: Complex Procedures and Problem-solving Skills Are not Tested}

It was established through interviews that complex procedures and problem-solving skills were not tested. The participants attributed this practice to lack of proper qualification in mathematics, and lack of proper moderation of formal assessments, both internally and externally.

\subsubsection{Sub-theme 1: Lack of Subject Knowledge}

Some teachers indicated that they did not receive proper training to teach mathematics, they were qualified teachers of course but for different subject areas. For example, T9 stated that:

Problem-solving skills were presented in one workshop in the form of games and ... what is this, learning to play in mathematics. I did not understand clearly, I am not trained to teach mathematics, so I don't have enough skills to make the subject simpler to learners through games. (T9).

T7 had this to say:

Because of high failure rate of learners and learners demotivated in the subject and us teachers having to account, I think that is the reason teachers do not include complex or high order questions in tests, we, however, try to use them in projects, where learners have a chance to ask for clarity purposes. (T7).

Contrary to T9 and T7's views, T2 pointed out that teachers must not compromise the policy requirements, they must test all the skills as stipulated in the CAPS document. T2 said:

Teachers must teach from simple to complex, in that way, complex skills can be learnt as one moves on with the learners. We cannot divert from the policy, it comes back when learners write common papers, from the department which incused those complex procedures and we then experience a high failure rate. (T2).

4.4.2. Sub-theme 2: The Six Cognitive Levels of Bloom's Taxonomy not Being Followed in the Setting of Formal Tests

T2 said the following regarding the six cognitive levels of Bloom's taxonomy:

This one really is a challenge to most teachers, yes they learnt about it during their training and maybe they did not understand the practical part of it. On the other side, the textbooks that we are using do not clearly stipulate the levels, it becomes a mammoth task now for the teacher to try and select which question goes with which level, maybe because of lack of time or lack of knowledge. (T2).

However, T4 and T8 had contradictory views. T4 commented:

I think these teachers do not engage with the CAPS document. The policy guides on how to select questions, they have to follow the policy. (T4).

T8 concurred by adding that:

The reason for this is not following curriculum, mmh, not curriculum, but the policy, if you go at the back of the policy, you see the guidelines and even the past exam papers stipulate that. I would say these teachers are not following the policy or they don't understand the policy itself. (T8).

4.4.3. Sub-theme 3: Lack of Proper Moderation of Formal Assessments, both Internally and Externally

Further analysis of interview data revealed that this part of assessment implementation was not properly done. Issues such as lack of proper moderation tools, moderators not being trained for the subject and lack of external moderation were highlighted. However, T2 was for the 
idea that moderation could be achieved at the school level if teachers practised moderating each other and took note of what was being done correctly and incorrectly. This is what T2 suggested:

Let us have the culture of monitoring each other formally or informally, highlight what is not being correctly done, share the good practices of moderation here at the school level. (T2).

Opposingly, T4 felt moderation was poorly performed by the Heads of Department (HODs). This is what T4 brought forward:

Moderation is done by subject heads that are not trained for mathematics. Like as it is, I am an HOD for intermediate phase mathematics, but I am trained for FET mathematics, so I don't think I can perfectly moderate for this phase. (T4).

Correspondingly, $\mathrm{T} 3$ raised the following factor: There are no proper moderation tools from the subject advisors, what exactly is supposed to be identified as correct or wrong, the tool we are using now for moderation is for all the subjects in the school, how can it be the same? I guess we are not doing it right when I was at another district; there was a different tool for each subject. (T3).

There was a revelation that there was no external moderation done by the mathematics subject advisors for formal assessments. For example, T2 said:

My tasks have never been moderated by my subject advisor, if I remember very well, only the tests for March, the quarterly test came from the department for grade 6, maybe that one was moderated by them. I set my own tasks, moderated here at the school level, that's it. (T2).

\subsection{Theme 5: Supporting and Guiding Learners after they Have Received Formal Tasks so as to Give them Quality Feedback}

Most of the teachers mentioned doing item and error analysis, then creating intervention strategies for the failing learners and recording the marks on the South African School and Administration Management System (SA-SAMS) so that all the stakeholders were informed of the assessment results.

\subsubsection{Sub-theme 4.1: Item and Error Analysis}

Item and error analysis was mentioned by most of the teachers as a tool which guides them on quality feedback to their learners. It helps them identify which concepts were achieved or not and what the causes were; they then create proper strategies thereafter. T1 elaborated on this as demonstrated in the following statement:

For me to give proper feedback, I complete the item and error analysis, for a test, I use the rubric for assignments and projects. The item and error analysis identifies what was achieved, not achieved and why. (T1).

$\mathrm{T} 3$ confirmed what $\mathrm{T} 1$ has said by stating that:

It is a requirement from the department that we do error analysis, yes it assists a lot, you identify mistakes to see where learners went wrong. (T3).

Similarly, this is what T8 added on the use of item and error analysis:

A teacher can only see the problem after monitoring the work that is marking. I ask my learners what was the problem, right there, they will tell me what the problem was; I can detect what I did not explain much. I don't depend on identifying them as wrong through the analysis; I detect my mistakes from what they are saying. (T8)

Inversely, $\mathrm{T} 7$ raised a concern that the template for item and error analysis is too complicated to complete and it is time-consuming. This is what he said:

I really don't see the reason why I should complete the item and error analysis form, it is complicated, it takes a lot of my teaching time, I can tell as I mark what my learners are struggling with and this will be reflected as corrections. If one goes through their corrections, difficult concepts will be seen. (T7).

\subsubsection{Sub-theme 2: Intervention Strategies}

Teachers emphasised the need for intervention strategies as the best follow-up and supportive measure for guiding learners after receiving their marked tasks. They stated it must be done soon after the item and error analysis was completed. This point was expanded by $\mathrm{T} 1$ who said:

When I have marked task, it depends on the type of assessment which was given. I will go back and look at what they have done well or not in terms of the topic and concept, then I take it from there, through teaching the concept again and testing for the second. (T1).

T3 brought forward the issue of motivating learners and going the extra mile as a teacher to try and support the learners who did not achieve the expected standard in that particular assessment. T3 said:

You know, you need to have that motivation, tell them it is possible, this is what you got, but it is not the end, show them enthusiasm, be prepared to go an extra mile and it must be visible to them that you are going an extra mile, appraise them for every achievement, have extra material, give extra time to the failing learners. (T3)

When asked about the issue of just pasting a memorandum, which is usually done by teachers as corrections, this is how $\mathrm{T} 5$ responded:

I think pasting of the memo, without evidence of working through the questions with learners is done 
by those teachers who want to emphasis to the supervisors that they are up to date with their work, everything is done. It's time really we become true to ourselves, like ...I am a little bit slow like we had sports now, we did not teach today, but teachers are scared to mention that, they want to fit in the timescale. Teachers must not be slaves of the pacesetter. Explain exactly where you are, corrections must be done without any hurry, repeat the concept if not yet understood by the learners. (T5).

\section{Discussion and Conclusions}

In the implementation of formal assessments in intermediate phase, mathematics teaching and learning is stipulated in the CAPS document [4]. Literature indicates that intermediate phase mathematics formal assessments are comprised of tests, examinations, projects assignments and investigations. The constructivism theory states that knowledge is acquired, whereas understanding is bolstered through the effective construction of mental frameworks [20]. The cognitive theory of Piaget is based on the notion that children can formulate their own perceptions of the world as they connect with different settings which, in turn, prompt assimilation and accommodation [43]. The theory has weighty implications for education, such as active engagement and exploration, unevenness of cognitive development and quality of thinking. Startlingly, it has been proven that learners are not actively engaged in the implementation of some of the assessment requirements in intermediate phase mathematics teaching and learning. Resultantly, learners lack critical and creative thinking which must be triggered by active engagement and exploration.

\subsection{Teachers' Inadequate Content and Pedagogical Knowledge}

The authors in [26] argue that formal assessment is ineffective in several classrooms owing to teachers' lack of sufficient knowledge and skills to execute them. Upon enquiry about complex procedures and problem-solving skills not being tested, the participants confirmed that the skill was not tested because of the lack of knowledge of the subject, on the part of the teachers. Reference [44] affirms that inadequate mathematical content knowledge might hinder teachers' capabilities to recognise and examine learners' mathematical reasoning. Additionally, the work in [15] indicates that a larger number of teachers do not know how to efficiently utilise assessment for tackling the learners' learning need, which is ascribed to their inadequate proficiency in this subject. The authors in [13] ratify teachers' poor content and pedagogical knowledge as a challenge which has a negative impact on formal assessment implementation, whereas teachers who have good content knowledge can communicate clear learning objectives. The work in [45] emphasises that teachers must possess abundant instructional knowledge for formal assessment. The authors in [14] point out that some teachers in South Africa lack proper qualifications and experience in the subjects they are teaching hence they are not competent and fail to implement assessments effectively. Similarly, reference [46] notes that teachers in South Africa and many other developing countries face major impediments regarding their lack of content knowledge of mathematics and the adequate skills of content application as they teach. Furthermore, the work in [47] reveals that a considerable number of mathematics teachers in South Africa have minimal understanding of curriculum delivery on the subject Additionally, the authors in [8] have found that some teachers' subject knowledge was insufficient to provide their learners with an adequate understanding of the subject discipline. Reference [48] mentions that in Zambia, a country with similar socio-economic conditions like South Africa, there is a lack of teacher networking; there is no sharing of ideas in teaching and learning. The authors of [14] confirm that teachers also do not receive adequate training in the implementation of formative assessments; hence they are highly challenged in this aspect. Inadequate training is closely related to lack of support for the concerned teachers. Reference [15] attests that the nature of support offered by the subject advisors in the challenges of formal assessment implementation is inadequate. The assessment policies came up with complete rules and procedures that became a challenge for teachers to tackle. The author in [49] mentions that intermediate phase mathematics teachers are still following the teacher-centred methods to implement assessments which do not tally with the CAPS. The authors recommend further training of teachers in the current pedagogy since they lack understanding in this aspect. Even though the policy illustrates the procedures to be followed, many South African mathematics teachers still find it challenging to follow and adapt to the new assessments system [49].

Augmenting the idea are the research findings of reference [25] who indicates that teachers did not understand the National Protocol on Assessments very well. Author [15] mentions that most of the teachers confirm that the policy document is confusing and complex. Likewise, the work in [3] contends that there is no additional information provided in the CAPS document explaining precisely the knowledge and skills needed in the enhancement of formal assessment or how these should be implemented in the classroom. Additionally, although there have been amendments in the policies, strategies, and different methods of intervention, most of the learners are still underperforming in mathematics in South African schools [50]. It has been discovered that 
most South African learners perform terribly in mathematics. This poor performance is due to teachers' poor knowledge of mathematics [51]. Similarly, the work in [18] notes that most teachers in the intermediate phase have not specialised in mathematics teaching and learning, they are instead trained to be competent in different subjects offered in the intermediate phase; hence they lack the knowledge of mathematics as a subject. Likewise, the authors of [52] claim that teachers encounter didactic challenges as they execute assessments. These difficulties can be encountered as teachers try to design tools such as rubrics or checklists.

\subsection{Implications of Cognitive and Social Constructivism}

This is averse to the CAPS which states that as a skill, learners should learn how to investigate, analyse and represent information [4]. The results reveal that some teachers do not consider unevenness of cognitive development of learners as they set formal assessments. This can be achievable through the application of Bloom's taxonomy as assessments are set to cater to all the cognitive levels. Some of the teachers are not well versed with the application of cognitive levels and it becomes difficult for them to set the tasks. Consequently, learners' thinking competencies can be lessened if not directed to comprehend on Bloom's level of thinking [53]. The emphasis of the level of understanding is underpinned by one of mathematics' specific aims, thus to establish a profound understanding of concepts so as to have a logic of mathematics as a subject [4]. Social constructivism clarifies worthwhile learning as one which takes place when people are exceptionally instructed on how to utilise their cultural psychological tools and have exposure on how to utilise them in turn to establish a universal awareness of phenomenon [54]. Furthermore, the results reveal that it is impossible to assist learners individually because of the class sizes. The findings evidently demonstrate that there is the inadequacy of social interaction between the teachers and their learners. This opposes the aspect of social context which states that learners develop new knowledge and meaning between the known and unknown through social interactions with knowledgeable peers or teachers. Language is clarified as a solution to conversations which serve to connect the teacher and learners. However, learners have limited English proficiency which hinders learners from understanding instructions for assessment.

\subsection{Teacher Proficiency in the Language of Learning and Teaching}

Furthermore, reference is made that the teachers' proficiency in conveying messages clearly will lead to learners' accelerated mastery of language [20]. This includes both spoken and written language. Inversely, data analysis discloses that the use of English language as a LoLT brings about a lot of challenges. Responses indicate that the LoLT makes it difficult for learners to understand questions, learners have difficulties in solving word problems due to language barriers and learners' performance is not up to standard because they cannot read and write in English. As such, teachers do not make use of appropriate mathematical language when testing learners for formal assessments. Literature confirms LoLT as a challenging issue in the teaching and learning of mathematics, hence being a barrier in the effective implementation of formal assessments. Reference [55] claims that fairness in assessment is based on the learners' proficiency in language, in this case, the English language as a medium of instruction. Moreover, learners are challenged in the oral, comprehension and writing areas since mathematics has its own terminology. Limited English proficiency poses a challenge for the learners to fully interpret given tasks. Resultantly, mathematics teachers face the challenge of achieving the twin objectives of teaching mathematics and English simultaneously [55]. Similarly, the work in [56] notes that the factors that influence learners' attainments in mathematics, especially in complex procedures and word problems, include language accuracy and word structure. Both factors call for English proficiency. This is confirmed by the DBE report on the Annual National Assessments (ANA) results where the Grade 6 learners' competency in word problems was only $9 \%$, indicating it was the most difficult skill to pass [57]. Author [56] attests that poor mathematics performance is due to learners' inability to read, write and compute. Reference [20] suggests that teachers must follow the Quality Teaching Model (QTM) to bolster the quality of teaching and learning. This model categorises teaching practices into three elements, namely the intellectual quality, significant knowledge, and the learning environment. The intellectual quality recommends that the significant role of the teacher is to assist learners with an understanding of new concepts in the subject area using pedagogical methods. This idea is supported by one of the specific aims of mathematics, which is to reinforce the intensive assimilation of the concept to fully understand mathematics as a subject. Significant knowledge comprises concepts, principles and fundamental ideas that are foundations of the subject taught. Furthermore, significant knowledge incorporates relationships that prevail between the fundamental ideas and other subjects [20] This element is supported by the CAPS as one of the specific aims, thus developing acquisition of distinct knowledge and capabilities essential to learn what is relevant to the subject [4]. Similarly, this is also encouraged by the authors in [58] as a principle of producing worthwhile mathematical tasks. The learning environment must be helpful for learners to work 
collaboratively, also develop interesting learning experiences which are challenging though [20]. This idea is underpinned by one of the specific aims of mathematics thus to broaden the motive for the love and curiosity for mathematics. Reference [20] also suggests that to teach effectively, teachers need to be knowledgeable with the subject and pedagogical content awareness. The knowledge of the subject will enable teachers to effectively communicate and engage with learners. Language has an essential part in the accomplishment of knowledge [54].

\subsection{Teacher Professional Development}

Reference [59] suggests that teachers need professional development to address their pedagogical challenges. Indisputably, literature reveals that teachers face various challenges in the implementation of formal assessments. These challenges include viewing assessments as an administrative burden on the teacher's part, lack of knowledge of formal assessments, teachers' poor content and pedagogical knowledge, lack of ongoing professional development, difficulties in understanding policies and the difficulties posed by the LoLT. Time-related issues in relation to teacher workload was a theme highly raised by most teachers. The authors in [60] have found that teachers were worried that preparation of learners' portfolios for assessments, for example, was time-consuming and it is confirmed that all assessment tasks take up a lot of time intended for teaching and learning. The study recommends that to teach effectively, teachers need to be competent in the subject area and be well versed with relevant content. Teacher training institutions should provide teacher development workshops on how to apply Bloom's taxonomy for them to implement formal assessments effectively. Mathematics subject advisors must hold various workshops to support teachers in the knowledge of formal assessments and be available for support in schools when needed. Reference [61] affirms that professional development which incorporates assessment as learning is essential to support teachers' assessment practices in the classrooms. Teachers must fulfil their role of being 'life-long learners'. They must make efforts to acquaint themselves with new developments in mathematics teaching and learning. They must invite subject advisors to their schools if they need support. In this way, they can improve their professional development and enhance effective teaching and learning in the classrooms.

\section{REFERENCES}

[1] Jacoby J.C., Heugh S., Bax C., Brandford-White C., Enhancing Learning Through Formative Assessment,
Innovations in Education and Teaching International, vol.51, n1. pp.72-83., 2014, DOI: $10.1080 / 14703297.2013 .771970$

[2] Gonzales R., Aliponga J. Classroom Assessment Preferences of Japanese Language Teachers in the Philippines and English Language Teachers in Japan, MEXTESOL Journal, vol.36, no.1, pp.1-19, 2012, https://www.mextesol.net/journal/index.php?page=journal \&id_article $=94$

[3] Kanjee A., Sayed Y. Assessment Policy in Post-Apartheid South Africa: Challenges for Improving Education Quality and Learning. Assessment in Education: Principles, Policy \& Practice, vol.20, no.4, pp.442-469, 2013, https://doi.org/10.1080/0969594X.2013.838541

[4] South Africa Department of Basic Education, Curriculum and Assessment Policy Statement Grades 4-6 Mathematics, Department of Basic Education, 2011.

[5] Wyk V., Wolhuter C., Learn to Teach: A Handbook for Teaching Practice. (2nd ed.), Oxford University Press, 2016.

[6] Donald D., Lazarus S., Moolla N. Educational Psychology in Social Context: Eco Systematic Applications in South Africa, ABC Press. 2014.

[7] Carnoy M., Chisholm L., Addy N., Arends F., Baloyi H., Irving M., Raab E., Reeves C., Sapire I., Sorto A, The Process of Learning in South Africa: The Quality of Mathematics Teaching in North West Province, Technical Report, Human Sciences Research Council, 2011.

[8] Taylor N., Taylor S. "Teacher Knowledge and Professional Habitus."

https://www.jet.org.za/resources/creating-effectives-school s-summary-1.pdf. (Accessed Jan, 18, 2019).

[9] McCarthy J. \& Oliphant R. 2013. Mathematics Outcomes in South African Schools. What are the facts? What should be done? https://www.cde.org.za/wp-content/uploads/2018/07/Math ematics-outcomes-in-South-African-schools-what-are-the-f acts-what-should-be-done-CDE-Report.pdf (accessed Apr. 8, 2018).

[10] South Africa Department of Basic Education, National Assessment Circular 3 of 2016, Department of Basic Education, 2016.

[11] Kanjee A., Pull up our socks! Developing effective assessment systems to improve learning for all. https://www.bridge.org.za/wp-content/uploads/2017/02/20 170221-Effective-assessment-systems-presentation-2.pdf (accessed Apr. 6, 2018).

[12] Dyer K., Measuring What Matters: Teach. Learn. Grow. The Education Blog. Formative Assessment, Classroom Tips, https://www.nwea.org/blog/author/kdyer/page/13/ (accessed Apr. 6, 2018)

[13] Brookhart S.M., Moss C.M., Lang B.A. Teacher Inquiry into Formative Assessment Practices: Assessments in Education: Principles, Policy and Practice, International Journal of Education, vol.17, no.1, pp.41-58, 2010, DOI: $10.1080 / 09695940903565545$

[14] Kuze M.W., Shumba A., An investigation into Formative 
Assessment Practices of Teachers in selected schools in Fort Beaufort in South Africa, South African Journal of Education, vol. 29, no.2, pp.159 -170, 2011, https://doi.org/10.1080/09718923.2011.11892966

[15] Kanjee A. Enhancing Teacher Assessment Practices in South African Schools: Evaluation of the Assessment Resource Banks. South African Journal of Education, vol.13, no.1, pp.73-89. 2015, https://doi.org/10.1080/1682 3200902940599

[16] Sayed Y., Kanjee A., Rao N., Assessment and Learning: Problems and Prospects, in Learning and Education in Developing Countries: Research and Policy for the Post-2015 UN Development Goals, Palgrave Macmillan, 2014, pp.91-109.

[17] Borich G.D., Effective Teaching Methods: Research-Based Practice, Pearson, 2014.

[18] Paulsen R., Dednam A. Challenges in Mathematics: Mathematical Literacy and Numeracy, in Addressing Barriers to Learning: A South African Perspective, Van Schaik, 2016, pp.

[19] Butt G., Making Assessment Matter, Continuum, 2010.

[20] Killen R., Teaching Strategies for Quality Teaching and Learning, Juta, 2015.

[21] Baird J., Hopfenbeck T.N., Newton P., Stobart G., Steen-Utheim A.T., State of the Field Review: Assessment and Learning. Norwegian Knowledge Centre for Education., Oxford University Centre for Educational Assessment, 2014.

[22] Kim R.Y., Kim K.Y., Lee M.H., Jeon J.H., Park J.W., The Challenges and Issues Regarding Extended ConstructedResponse Questions: Korean Teacher's Perspective, Proceedings of the 12th International Congress on Mathematical Education, Topic Study Group 33, 2012, pp. 6631-6640.

[23] Sparks S.D., 2011. Researchers Probe Causes of Math Anxiety, https://www.edweek.org/ew/articles/2011/05/18/ 31mathep.h30.html. (accessed Dec. 4, 2019).

[24] Boaler J., Fluency Without Fear: Research Evidence on the Best Ways to Learn Math Facts, https://www.mathnasium. com/math-fluency-without-fear, (accessed Dec. 4, 2019).

[25] Lumadi M.W., Challenges Besetting Teachers in Classroom Assessment: An Exploratory Perspective, South African Journal of Education, vol. 34, no. 3, pp.211-221. 2013, https://doi.org/10.1080/09718923.2013.11893132

[26] Brown G.T.L., Kennedy K.J., Fok P.K., Chan J.K.S., Assessments for Learners Improvement: Understanding Teachers' Concepts and Practices of Assessments: Assessments in Education, Principles, Policy and Practice, vol.16, no.3, pp. 347- 363, 2009, https://doi.org/10.1080/0 9695940903319737

[27] South Africa Department of Basic Education, Guidelines for Incisive Teaching and learning, Department of Education, 2010.

[28] Friend M., Bursuck W.D., Including Students with Special Needs. A Practical Guide for Classroom Teachers, Allyn \& Bacon, 2006.
[29] Brodie K., The Power of Professional Learning Communities, Education as Change, vol.17, no.1, pp.5-18. 2013, DOI: $10.1080 / 16823206.2013 .773929$

[30] Dempsey K., Beesley A.D., Clark T.F., Tweed A., Authentic Student Work Samples Support Formative Assessment in Middle School, in Annual Perspectives in Mathematics Education: Assessment to Enhance Teaching and Learning, NCTM, 2015, pp.157-166.

[31] Geist E., The Anti-Anxiety Curriculum: Combating Math Anxiety in the Classroom, Journal of Instructional Psychology, vol.37, no.1, pp.24-31, 2010, https://www.researchgate.net/publication/281089312_The Anti-Anxiety_Curriculum_Combating_Math_Anxiety_in_the Classroom

[32] Piaget J., The Early Growth of Logic in the Child, Routledge and Kegan Paul, 1964.

[33] Borich G.D., Tombari M.L., Educational Psychology: A Contemporary Approach, Longman, 1997.

[34] Eggen P.D., Kauchak D.P., Educational Psychology: Windows on Classrooms. Pearson, 2016.

[35] Ladewig W., Potgieter R., Pretorius J., Oxford Successful Mathematics Teacher's Guide Grade 6, Oxford University Press, 2012.

[36] Jooste C., Press K., Slamang M., Smuts C., Study \& Master. Mathematics Learner's Book Grade 6, Oxford University Press, 2012.

[37] Piaget J., The Origin of Intelligence in the Child, Routledge and Kegan Paul, 1953.

[38] Creswell J.W., Educational Research: Planning, Conducting and Evaluating Quantitative and Qualitative Approaches to Research, (5th ed), Merrill/Pearson Education, 2015.

[39] Creswell J.W., Qualitative Inquiry and Research Design: Choosing Among Five Traditions, (3rd ed), Sage, 2013.

[40] Patton M.Q., Qualitative Research and Evaluation Methods: Integrating Theory and Practice, (4th ed), Sage. 2014.

[41] Gay L.R, Mills G.E., Airasian P.W., Educational Research: Competencies for Analysis and Applications, Pearson, 2011.

[42] Maree K., Pietersen J., Sampling, in Maree K., First Steps in Research. (3rd ed.), Van Schaik, 2020, pp.213-224.

[43] Berk K.L., Child Development, (9th ed.), Pearson, 2012.

[44] Putnam R.D., Our Kids: The American Dreams in Crisis, Simon \& Schuster, 2015.

[45] Ruiz-Primo M.A., Informal Formative Assessment: The Role of Instructional Dialogues in Assessing Learners' Learning. Studies in Educational Evaluation, vol. 37, no.1, pp.15-24, https://doi.org/10.1016/j.stueduc.2011.04.003

2011

[46] Rowland T., Ruthven K., Mathematical Knowledge in Teaching, Springer, 2011.

[47] Stols G., Ferreira R., Pelser A., Olivier W., Van der Merwe A., De Villers C., Venter S., Perceptions and Needs of 
South African Mathematics Concerning their Use of Technology for Instruction, South African Journal of Education, vol.35, no.4, pp.1-13, 2015, http://dx.doi.org/10.15700/saje.v35n4a1209

[48] Kapambwe W., The Implementation of School-Continuous Assessment (CA) in Zambia, Educational Research and Reviews, vol.5, no.3, pp.99-107, 2010, http://www.academicjournals.org/ERR.

[49] Remesal A., Primary and Secondary Teachers' Conceptions of Assessment: A Qualitative Study. Teaching and Teacher Education vol.27, no.2, pp.472-482, 2011.DOI: 10.1016/j.tate.2010.09.017

[50] Motala S., Morrow S., Sayed Y., Gauteng Department of Education: A Policy Review, in Twenty Years of Education Transformation in Gauteng 1994 to 2014: An Independent Review, Gauteng Department of Education, 2014, pp.15-35.

[51] Pournara C., Hogen J., Alder J., Pillay V. Can Improving Teachers' Knowledge of Mathematics Lead to Gains in Learners' Attainment in Mathematics? South African Journal of Education, vol.35, no.3, pp.1-10, 2015, DOI: $10.15700 /$ saje.v35n3a1083

[52] Suurtamm C., Thompson D., Kim R., Moreno L., Sayac N., Schukajlow S., Silver E., Ufer S, Vos P., Assessment in Mathematics Education: Large Scale Assessment and Classroom Assessment, Springer, 2016.

[53] Jacobs M., Aims and Objectives, in Teaching-Learning Dynamics, Pearson Education, 2016, pp.311-343.

[54] Vygotsky L., Mind in Society: The Development of
Higher Mental Processes, Harvard University Press, 1978.

[55] Botes H., Mji A. Language Diversity in the Mathematics Classroom: Does a Learner Companion Make a Difference? South African Journal of Education, vol.30, no.1, pp.123-128, 2010, DOI: 10.15700/saje.v30n1a318

[56] Spaull N. South Africa's Education Crisis: The Quality of Education in South Africa 1994-2011, Centre for Development and Enterprise, 2013.

[57] South Africa Department of Basic Education, Report on the annual national assessments of 2011, Department of Basic Education, 2011.

[58] Anthony G., Walshaw M., Characteristics of Effective Teaching of Mathematics: A view from the West, Journal or Mathematics Education, vol.2, no.2, pp.147-164, 2009, https://www.researchgate.net/publication/228743535 Char acteristics_of_Effective_Teaching_of_Mathematics_A_Vi ew_from_the_West

[59] Du Plessis E., Do Teachers Receive Proper In-Service Training to Implement Changing Policies: Perspective from the South African Case? Comparative Education \& History of Education, pp.53-58, 2013, https://files.eric.ed.gov/fulltext/ED567124.pdf

[60] Chisholm L., Hoadley M., Prinsloo C, Mosia D., Rule S., Teacher Workload in South Africa, HSRD, 2009.

[61] Van der Nest A., Long C., Engelbrecht J., The Impact of Formative Activities on the Development of Teacher Agency in Mathematics Teachers, South African Journal of Education, vol.38, no.1, pp.1-10, 2018, http://dx.doi.org/10.15700/saje.v38n1a1382 